\title{
CONFLITOS ORGANIZACIONAIS ENTRE GERAÇÕES: UM ESTUDO EMPÍRICO COM A EQUIPE DE DESENVOLVIMENTO DE SOFTWARE DO IFRN
}

\author{
L. F. L. G. COSTA', C. M. MENDONÇA², G. RODRIGUES JR³ , M. V. P. ARAÚJO 4, J. M. L. ALLOUFA 5 e R. C. SILVA 6 \\ ${ }^{1,6}$ IFRN, ${ }^{2}$ UNP, ${ }^{3,4,5}$ UFRN \\ lucia.lucio@ifrn.edu.br,cmmarcio@unp.br, giovanirj@uol.com.br, valeriaraujo@ymail.com.br , \\ jalloufa@yahoo.com.br, raiicostasilva@gmail.com \\ Artigo submetido em junho/2012 e aceito em maio/2014 \\ DOI: $10.15628 /$ holos.2014.898
}

\section{RESUMO}

O presente artigo tem o objetivo de compreender como as relações entre os indivíduos de gerações diferentes são desenvolvidas através do trabalho em equipes de TI. Para tanto foi realizada uma pesquisa qualitativa através da técnica de análise conteúdo. Observou-se que o conhecimento específico pode ser uns dos balizadores da liderança ou da proporão de novos conflitos e que as gerações $Y$ e $X$ não apresentam distinções, porém o conhecimento específico em equipes de TI é quem gera distinções no comportamento.

PALAVRAS-CHAVE: Conflito Intergeracional, trabalho em equipe, tecnologia da informação.

\section{ORGANIZATIONAL CONFLICT BETWEEN GENERATIONS: AN EMPIRICAL STUDY WITH A TEAM OF SOFTWARE DEVELOPMENT IFRN}

\begin{abstract}
This article aims to understand how working in teams of IT develops relationships between individuals of different generations. For this purpose a survey was conducted by qualitative content analysis technique. It was observed
\end{abstract}

that the specific knowledge can be a guide for the leadership of or propose new conflicts and generation $Y$ and $X$ have no distinctions, but the expertise is in IT teams that create distinctions in behavior.

KEYWORDS: Intergenerational Conflict, teamwork, information technology. 


\section{INTRODUÇÃO}

As organizações enfrentam ambientes competitivos, os clientes e cidadãos estão ainda mais exigentes na qualidade de serviços e produtos. As organizações se adaptam as transformações em curso, que as colocam diante de um desafio de seguir motivando e envolvendo pessoas a desenvolverem comprometimento onde atuam.

Além disso, alterações no cenário econômico geram mudanças que acarretam na redução de postos de trabalho, tais como: terceirização, fusões, aquisições e incorporações, e o uso cada vez mais intensivo da tecnologia. Essas transformações acabam gerando de alguma forma, uma competitividade no ambiente organizacional, e as organizações, mais seletivas, buscam os profissionais mais preparados. Outra característica que pode gerar mais competitividade é o desafio de integrar quatro gerações inteiramente distintas entre si, dentro de um mesmo ambiente organizacional.

Nesse sentido observa-se a relevância de analisar variáveis relativas às relações interpessoais que dinamizam o corpo laboral. A dinâmica organizacional, muitas vezes, pode gerar conflitos de interesses entre os indivíduos.

Os fatores como valores, crenças sobre as organizações, ética de trabalho, os motivos pelos quais trabalham as metas e desejos na vida profissional, o comportamento no trabalho afetam de forma similar o padrão de resposta a situações e instituições, dependendo de cada estrutura das gerações. $O$ agrupamento de gerações recebeu o nome de coortes, onde a divisão mais conhecida no meio acadêmico é a dos baby boomers, que são aqueles nascidos até 1964, a Geração X, composta por aqueles nascidos entre 1965 e 1977, a Geração Y, nascida a partir de 1978 e a Geração Z, nascida após a década de 90 . Os indivíduos das gerações possuem comportamentos semelhantes que para Cavazotte, Lemos e Vianna (2010) são responsáveis por fazer da estrutura empresarial e social ações peculiares e únicas em determinado período de tempo.

Esse aumento da competitividade no ambiente organizacional, e o convívio entre 4 gerações distintas com objetivos, comportamentos e atitudes diferentes, pode ocasionar conflitos, que podem ser negativos ou positivos para as organizações, dependendo de como são geridos.

Diante dessas perspectivas o presente artigo tem como propósito apresentar uma análise acerca dos conflitos organizacionais e seus potenciais geradores observando as diferentes gerações (coortes). Para tanto, foi realizada uma pesquisa qualitativa junto a uma equipe de tecnologia da informação (TI) do Instituto Federal de Educação Ciência e Tecnologia do Rio Grande do Norte (IFRN).

A escolha por campo empírico se deu em função das características intrínsecas a dinâmica da renovação do conhecimento, que demanda dos indivíduos renovem o conhecimento de forma recorrente e independente de sua geração. Nesse sentido a equipes de TI, cuja as tarefas são divididas de forma a executar um projeto maior, é um campo fértil para informações sobre inovação do conhecimento, conflitos entre gerações e relações interpessoais.

Muitas pesquisas tem evidenciado as mudanças estruturantes no comportamento laboral de muitas empresas na área de tecnologia da informação o que passa por um processo de transformação dos modelos convencionais nos quais são desenvolvidas estratégias e novas formas 
de aplicações organizacionais. O estudo também visa observar que aspectos relativa a mudança de comportamento se também pode ser evidenciado no setor público, uma vez que mesmo com características próprias voltadas para o conhecimento, dessas equipes, elas estão inseridas em um contexto institucional que respeitam aspectos relativos a burocracia Weberiana, assim, os estudo além de abordar a convergência teórica de conflito apresenta um recorte significativo em relação ao seu campo empírico uma vez que a investigação é realizada em um instituição pública.

\section{REFERENCIAL TEÓRICO}

As relações interpessoais entre gerações em ambientes organizacionais oportunizam condições de avaliação do comportamento coletivo de uma equipe, pautados em modelo mentais dos indivíduos. Assim a análise da convergência teórica para a discussão empírica fundamenta bases de dimensões e categorias que podem ser extraído do processo circular de pesquisa de geração de compreensão do conhecimento sobre conflitos interpessoais.

\subsection{GERAÇÕES}

A cada geração são atribuídos momentos marcantes na evolução da sociedade, como a guerra do Vietnã, o surgimento dos movimentos feministas e a criação dos anticoncepcionais, fatos presenciados pela geração conhecida por baby boomers (CONGER, 1998). Já a geração X, segundo Lombardia et al (2008), presenciou, por exemplo, a Guerra Fria, a derrocada do muro de Berlim, o surgimento da AIDS e toda a mudança de conceitos atrelada a esse tema. Em seguida, encontramos a geração Y, que devido aos avanços tecnológicos viu emergir, segundo Toffler (2001) a era da sociedade da informação e a geração $Z$.

Veloso et al (2008) relatam que não há muita concordância, entre os autores que estudaram o tema, com respeito aos períodos de nascimento de cada geração, por isso neste artigo adotou-se a designação proposta pela autora, que especifica a seguinte cronologia para as gerações: baby boomers, nascidos até 1964, entre 1965 e 1977 a geração X, a geração Y nascida a partir de 1978, e a geração Z, nascida a partir de 1990.

Barbosa e Cerbasi (2009) afirmam que, para a geração baby boomers, fatores como tempo e produção encontram-se associados à vida do homem uma vez que, quando mais se produza, maior será o reconhecimento e mais dinheiro poderá ser ganho, rejeitam o equilíbrio pessoal a uma posição inferior em relação ao desempenho profissional.

Já a Geração X, que segundo Souza (2011), busca o sucesso, mesmo que não sejam materialistas, valorizam à experiência do que à aquisição, possuem uma preocupação maior com a satisfação no emprego do que em sacrificar sua felicidade e o crescimento pessoal em troca de uma promoção o que, entre outros fatores, acaba se traduzindo na busca por melhor qualidade de vida.

A geração mais nova que é a Y, possui características muito marcantes, que acaba gerando um embate cultural que aparece devido a conflitos de poder, ao serem gerenciadas ou gerenciarem pessoas de outras gerações. Este desacordo pode ser justificada pelos valores, experiências e crenças de cada geração. Embora seja uma geração mais acostumada com mudanças, menos inclinada a priorizar a segurança no trabalho, mais ansiosa por novos desafios, e mais tolerante com os erros do que as gerações anteriores (CAVAZOTTE, LEMOS, VIANNA, 2010). 
Para Souza (2011) a última geração a Z, surgiu nos anos 1990 e um dos aspectos marcantes é a velocidade com que obtêm as informações e a fácil irritabilidade quando estas não lhes chegam rapidamente. Pesquisadores acreditam que são pessoas na sua maioria individualistas, e que terão grande dificuldade em realizar trabalhos em equipe e em compreender a si mesmos.

Com isso, poder-se-ia concluir que um conjunto de pessoas com idades aproximadas forma uma geração, no entanto, conforme observam Lombardia et al (2008), a aproximação de idade não é suficiente para defini-la, fatores como valores e princípios comuns, vivências históricas macrosociais partilhadas, visão de vida e de mundo, cenário sociopolítico devem ser observados em sua definição.

É essa soma de valores, comportamentos e características que forma uma geração e a diferencia das demais, pois, para Vasconcelos et al (2009), esse conjunto de coisas influencia o modo de ser e viver dos indivíduos nas sociedades, acarretando mudanças e marcando sua passagem para uma nova geração. Além de influenciarem no convívio das organizações.

\subsection{OS PROCESSOS DE CONFLITO NAS ORGANIZAÇÕES}

Trabalhar em grupo, principalmente quando não há integração, torna o ambiente propício ao surgimento de conflitos, tendo em vista as diferenças de opiniões, pensamentos e interesses, que podem surgir graças à presença de outras partes. Nesse sentido, Robbins (2005, p. 326) define conflito como um "processo que tem início quando uma das partes percebe que a outra parte afeta, ou pode afetar, negativamente, alguma coisa que a primeira considera importante".

Ainda com relação ao antagonismo entre as partes, Rubin et al (1994), afirma que o conflito surge quando uma parte percebe que suas aspirações são incompatíveis com outras partes. E que a gravidade do conflito é de acordo com as alternativas disponíveis para amenizar as partes. Quanto menor o número de alternativas, maior é a intensidade dos conflitos.

Geralmente, quando define-se conceitualmente conflito, se imagina um embate de interesses entre pessoas, onde prevalece um ambiente hostil. Entretanto, isso não tem que ser verdade sempre. A divergência de opiniões pode vir a ser benéfica para a organização. Segundo Ferreira (2007, p. 5) "os conflitos nas organizações não têm que ser necessariamente destrutivos", porém, para que esse processo seja conduzido de maneira eficaz é fundamental que todas as partes envolvidas estejam alinhadas sobre sua natureza dentro do ambiente organizacional.

A primeira refere-se aos benefícios para a organização e para o indivíduo, são conflitos construtivos, segundo Hitt, Miller e Coella (2006) promovem maior espontaneidade e comunicação, facilitam a resolução de problemas e tomada de decisão, estimulam a mudança e criatividade, dentre outros benefícios. Em contrapartida, a segunda forma de conflito atrapalha o desempenho do grupo, são conflitos destrutivos, e que podem interferir negativamente no desempenho, prejudicando os objetivos e metas da organização. As pessoas nessa forma de conflito passam a exercer poderes individuais, agindo para alcançar os próprios objetivos em detrimento da promoção dos objetivos organizacionais e do grupo, provocando efeitos negativos no que confere às relações interpessoais.

Para identificar se um conflito é funcional ou disfuncional é preciso conhecer os tipos de conflito que, em conformidade com Hitt, Miller e Colella (2006) estão dispostos em três tipos: 
Conflito de relacionamento, que surge em meio a diferenças pessoais, como diferentes valores, personalidades, objetivos e assim por diante. O conflito de processo que está relacionado à responsabilidade e atribuições do trabalho. O conflito de tarefas está ligado ao conteúdo ou essência do trabalho e aos seus objetivos e metas.

Conhecer e saber lidar com tais processos torna-se por sua vez primordial para haver uma gestão de conflitos que busque manter a eficiência dos grupos nas organizações. Diagnosticar as causas de um conflito não é tarefa fácil, uma vez que a natureza do conflito pode estar relacionada a inúmeras variáveis, onde diversos fatores podem se interligar, ajudando a promovê-lo. Para Hitt, Miller e Colella (2006) esses fatores podem ser estruturais, fatores de comunicação, cognitivos, características individuais e históricas das relações entre as partes.

\subsection{O LADO POSITIVO DO CONFLITO: AGENTE IMPULSIONADOR DE INOVAÇÃO}

Foram apresentados aqui anteriormente aspectos ligados à natureza do conflito dentro do ambiente organizacional. Embora as pessoas sejam resistentes a pensar em conflito como algo positivo, em conformidade com Ferreira (2007), o gerenciamento eficaz pode ser orientado para 0 questionamento dos processos de conflito, visando melhorias e incentivando o desenvolvimento dos conhecimentos e habilidades dos membros das equipes de trabalho, contribuindo assim para o surgimento de processos inovadores nas organizações.

Os sinais de conflitos construtivos podem ser observados quando há melhora na qualidade das decisões tomadas, a criatividade e inovação são estimuladas e o interesse e curiosidade dos membros das equipes fomentam um ambiente onde os problemas são abertamente apresentados e solucionados, as tensões diminuem e onde prevalece um cenário motivador de trabalho. Dessa forma o conflito agirá como força propulsora da mudança e inovação, tornando o trabalho mais eficiente e satisfatório no ambiente organizacional.

Para Cohen e Fink (2003), mesmo que o conflito possa causar onerações, em alguns casos, é parte necessária para se conseguir a consideração plena de pontos de vistas legitimamente diferentes. E quando problemas entre grupos/gerações se tornam conflitos devastadores, eles precisam ser tratados visando reduzir o conflito e permitir a cooperação.

\subsection{TRABALHO EM EQUPE}

Um grupo é nada mais que a reunião de pessoas com responsabilidades individuais que compartilham informações necessárias para o desempenho de cada membro a fim de atingir determinado objetivo através do uso aleatório das variadas habilidades dos componentes, onde os fatores sinergia e integração são ausentes. Por outro lado, equipe é o oposto de tudo isso, logo, convém às organizações criar equipes de trabalho em detrimento de grupos.

Maximiano (2004) e Gerson (2006), ressaltam que toda organização é um grupo de pessoas, e muitas são montantes de grupos, assim, todo indivíduo numa organização faz parte de um grupo, formalmente estabelecido pela organização para alguma atividade (grupos formais) ou criado pelos próprios indivíduos com finalidade própria (grupos informais). Complementando, em concordância Giacchetto (2008), afirma que toda equipe é um grupo, mas nem todo grupo é uma equipe, o desafio passa a ser então como transformá-lo em equipe. 
Segundo Vergara, (2009, p. 190), “Um conjunto de pessoas trabalhando juntas é apenas um conjunto de pessoas. Para que se torne uma equipe é preciso que haja um elemento de identidade, elemento de natureza simbólica, que una as pessoas", esse elemento, capaz de unir as pessoas, pode ser encontrado nos processos, normas, objetivos, na situação, etc., não visa homogeneizar todo mundo, mas fazer com que as diferenças individuais sejam integradas e se sobressaiam ao grupo, formando uma equipe.

Para isso, é fundamental a presença de um orientador que conduza eficazmente esse processo. Nesse sentido, Bergamini (2005, p. 123) relatou que "é indispensável para qualquer grupo que almeja atingir sua eficácia que possua alguém para orientá-lo na direção desejada."

\subsubsection{TIPOS DE EQUIPE}

Uma vez conduzido o processo de transformação de grupo em equipe, ela pode se prestar a realizar variadas coisas, sendo que nas organizações, segundo Robbins (2005), encontramos quatro tipos mais comuns:

Equipes de soluções de problemas: equipe voltada para discussão, seja sobre eficiência de um processo, a qualidade ou solucionar algum problema; trocam ideias e dão sugestões, mas raramente tem autonomia para implementação unilateral das sugestões;

Equipes auto-gerenciadas: semelhantemente às equipes de solução de problemas, se volta também para discussão sobre melhorias e solução de problemas, com a vantagem de ser interdependente e poder implementar as sugestões propostas sem necessitar de supervisão. Planejamento e cronograma de trabalho, delegação e controle do trabalho, tomada de decisão e implementação são algumas características desse tipo de equipe.

Equipes multifuncionais: tem formação de caráter temporário por funcionários de diferentes setores ou departamentos com o mesmo nível hierárquico. É uma forma eficaz para indivíduos das mais diversas áreas de uma mesma empresa (ou empresas diferentes) trocar informações, propor ideias para solucionar problemas e, principalmente, coordenar projetos complexos;

Equipes virtuais: os membros nesse tipo de equipe usam a tecnologia da informática, através de meios de comunicação como redes internas e externas, correio eletrônico, videoconferência, dentre outros, para manter o contato entre si, suprindo a distância provocada pela dispersão física dos componentes. Essas equipes podem desenvolver as mesmas tarefas realizadas pelas equipes supramencionadas, mas estão mais sujeitas a falhas de comunicação, como por exemplo, falta de clareza muitas vezes melhor expressa pessoalmente.

Como afirmou Bergamini (2005), para que o grupo alcance seus objetivos é preciso que alguém os oriente, logo, nesse processo de transformação do grupo em equipe, é responsabilidade do gestor ou líder que represente essa figura, ter o conhecimento sobre os tipos de equipes nas organizações. 


\subsection{DIFERENTES PERCEPÇÕES DO TRABALHO ENTRE INTEGRANTES DE GERAÇÕES X E Y}

As organizações vivem atualmente um momento histórico, onde é possível encontrar profissionais de três gerações - baby boomers, $\mathrm{X}$ e $\mathrm{Y}$ - trabalhando juntas. Definir uma geração não é tarefa fácil, que dizer de diferenciar uma geração de outra. Cada vez mais as diferentes gerações estão convivendo dentro das empresas, cada qual com suas características e valores, resultando muitas vezes em conflitos (LOMBARDIA et al , 2008).

Essas diferenças são realmente visíveis quando comparadas as gerações. Os profissionais da geração X são, por exemplo, segundo Zemke et al (2000), indivíduos ainda muito conservadores, que valorizam bastante a família, bem como o emprego, têm aversão à supervisão e não são bons cumpridores de prazos, focam mais nos objetivos, preferem o ambiente informal do trabalho. São autoconfiantes, positivistas e céticos, mas é possível perceber certa dose de criatividade em tais pessoas.

Se novas circunstâncias que se apresentaram forçaram os integrantes da geração $X$ a serem mais criativos e desenvolverem novas habilidades, a geração $Y$ já nasceu, segundo Tapscott (2010), imersa na interatividade, na hiperestimulação e no ambiente digital. Devido esses fatores, os indivíduos dessa geração são mais informados e possuem um nível de educação frequentemente mais elevado que os integrantes das gerações anteriores. Como traços e características dessa geração os autores ainda relatam a definição clara de seus objetivos pessoais e profissionais, utilizam bem suas habilidades, e estão sempre em busca de conhecimento, se mantêm atualizados, são flexíveis e não tem medo da inovação, pois são acostumados à mudança, veem as novas tecnologias como facilitadoras no ambiente de trabalho. Também mantêm o foco nos resultados e se preocupam em otimizar o tempo hábil para a realização das tarefas, buscando sempre agregar inovação ou algo que lhes conceda crédito.

No entanto, embora as pessoas dessa geração priorizem as relações humanas e estejam mais ligadas ao lado social, em contrapartida elas não são tão comprometidas, são muito reivindicativas, e buscam sempre sua própria comodidade. (COIMBRA; SHINKMANN, 2001; PORTES, 2009; VELOSO et al, 2008; LOMBARDIA, 2008).

Segundo Veriguine et al (2010) essa geração vem influenciando de maneira mais direta os destinos da sociedade. Como resultado disso, em concordância com Coimbra e Schikmann (2001), observa-se a revolução que está transformando o meio organizacional, pois quando os jovens dessa geração começam a integrar o quadro funcional de uma organização eles levam consigo uma cultura diferente e novas visões sobre o conceito de trabalho, inovação e hierarquia. Esses mesmos autores relatam também que os integrantes da geração $Y$ "nasceram mergulhados nas novas tecnologias, às quais as gerações anteriores estão ainda tentando se acostumar e entender" (COIMBRA; SCHIKMANN, p. 6).

O abismo tecnológico entre gerações pode ser motivo de conflito, além do que a própria injeção de novos conceitos pode vir a causar atritos e fomentar um ambiente de conflito, uma vez que os antigos funcionários podem sentir-se ameaçados com as novas mudanças. E ainda, fatores como princípios e valores, ética de trabalho, crenças sobre a organização, os motivos pelos quais trabalham objetivos e ambições profissionais e o modo como se comportam no ambiente corporativo afetam as relações de trabalho entre as gerações. 


\section{ASPECTOS METODOLÓGICOS}

A presente pesquisa pode ser caracterizada descritiva e exploratória e foi fruto do desenvolvimento de uma análise qualitativa realizada com a equipe de $\mathrm{TI}$, mais especificamente de desenvolvimento de software do IFRN. Foram estabelecidas pré-categorias de análise com o intuito de apreender o maior número de informações que representasse relação conceitual e prática com o estudo. Nesse sentido foram estabelecidas quatro categorias básicas e norteadoras da pesquisa teórica que possibilitou a construção de um instrumento de coleta de dados semiestruturados, que são: a) Estruturas de comportamento entre Coortes (grupos identificados por características de sua geração), que visa compreender o padrão do comportamento dos indivíduos e identificar características comuns ao coortes; b) Relações interpessoais e trabalho em equipe, que visa estudar a forma sobre a qual os indivíduos da equipe se relacionam e como desenvolve o trabalho em equipe; c) Conflitos e suas possíveis soluções, que almeja Identificar os conflitos; e, d) Potenciais geradores de conflitos, que visa Identificar possíveis questões que podem potencializar situação de conflitos no ambiente organizacional, tais como: gerencia equivocada; busca por objetivos distintos da organização; busca pelo poder; diferença etária; conhecimento específico e outros.

Com o apoio das categorias iniciais foi elaborado uma entrevista semiestruturada, utilizada para orientar a investigação que foi desenvolvida de forma que os entrevistados pudessem realizar o seu discurso em profundidade, de acordo com suas percepções acerca de cada tema. Foram realizados dois grupos focais com grupos de níveis hierárquicos distintos da equipe de TI. O primeiro grupo foi a equipe do desenvolvedores (nível operacional) com cinco integrantes e o segundo grupo foi com a equipe da diretoria de TI (nível estratégico), também com cinco componentes.

Após a realização das entrevistas foi feita a transcrição literal dos grupos focais, dos quais através de uma análise de discurso (metodologia apropriada para análise por meio de grupo focal)(GIL, 2002) oportunizou a identificação de mais duas categorias: a) Democratização das informações, que verificam as soluções de conflitos acerca de ferramenta tecnológica oportunizam a divulgação de novos conhecimentos; e b) Conflito com clientes internos que verificam os conflitos existentes com os consumidores de das ferramentas que resistem as mudanças tecnológicas.

Após a identificação dessas categorias, foram estruturados os resultados voltados para convergência teórica conforme observados na próxima secção.

\section{APRESENTAÇÃO E ANÁLISE DE RESULTADOS}

A seção apresenta uma discussão em relação aos resultados obtidos observando as categorias de análise supracitadas e que aspectos foram de maior relevância para a compreensão dos conflitos organizacionais de diferentes gerações em equipes de TI no setor público

\subsection{ESTRUTURA DE COMPORTAMENTO ENTRE COORTES}

A perspectiva teórica definida em relação aos coortes, demonstram que existe mudança no padrão do comportamento de acordo com as experiências históricas vivenciadas pelo indivíduos, 
no caso da equipe em estudo os entrevistados nasceram entre intervalo de 1972 e 1992, sendo a maior parte deles nascido após 1982. Portanto temo um intervalos de idades dos 39 a 19 anos.

Observando a categorização teórica, dois indivíduos estariam na geração $X$ nascidos entre 1965 e 1977, sete na geração Y, nascidos entre 1978 e 1989 e um indivíduo da geração Z nascida a partir dos anos 90 .

A rigor a equipe tanto no nível operacional, bem como do nível estratégico, se mostraram homogêneos entre si em relação ao seu posicionamento sobre a percepção de conflito organizacional. $\mathrm{O}$ que se pode perceber em se tratando da equipe de $\mathrm{TI}$, o relacionamento entre indivíduos de coortes diferentes não oportunizam conflitos, uma vez que consideram que o trabalho é voltado a pesquisa e desenvolvimento de softwares, é uma atividade semelhante a ser autodidata e essa característica era comum a equipe.

Quando questionados segundo a sua percepção do conflito de gerações poderiam oportunizar conflitos, eles responderam que sim uma vez que vivenciam conflitos com seus clientes internos (funcionários de outros departamentos), que resistem as mudanças de inovações tecnológicas e ficam presos a métodos e sistemas legados.

Segundo a percepção dos indivíduos as diferenças de comportamento entre os indivíduos de gerações diferentes existem, isso no entanto, não é considerado um fator de conflito entre os integrantes da equipe por terem padrões equivalentes de conhecimento acerca das ferramentas tecnológicas (software de desenvolvimento) utilizados no trabalho, embora percebam que externamente (em outras organizações) essa diferença etária gera conflitos na utilizações de ferramentas tecnológicas mais modernas.

\subsection{RELAÇÕES INTERPESSOAIS E TRABALHO EM EQUIPE}

O desenvolvimento de software é uma tarefa onde o trabalho é feito em equipe, uma vez que atividade do setor se desenvolve através do modelo de gestão matricial, que prioriza execução de projetos. Isso, no entanto não quer dizer que os indivíduos desenvolvam essas tarefas em conjunto.

Embora exista um layout favorável a uma comunicação dinâmica nas salas, a equipe tem horários flexíveis de trabalhos e raramente estão em sua totalidade em um mesmo ambiente, o que há é um fracionamento de tarefas, no qual cada indivíduo se responsabiliza por concluir sua etapa em um prazo determinado para não comprometer as etapas subsequentes.

Eles alegam o fato de trabalharem muito com pesquisa de desenvolver ferramentas, o trabalho passar a ser muito individual, embora haja discussão de ideias, recursos e caminhos pelos quais escolhem utilizar e eventualmente alguém expõe que já fez algo parecido e troca experiências, porém essa não é uma prática recorrente.

Nesse sentido percebe-se que o trabalho em equipe é uma situação compulsória da própria natureza do trabalho a ser desenvolvido, isso, no entanto não se dá em propriamente em equipe, pois cada responsável por uma área faz o seu trabalho de maneira isolada. 


\subsection{CONFLITO E SUAS SOLUÇÕES}

Quando questionados em relação a percepção que cada um tinha sobre conflitos, a maioria respondeu que ocorria quando as partes divergiam suas opiniões sobre determinada matéria, vinculando isso principalmente a aspectos de subordinação e dependência.

Essa percepção pode está atrelada a dois aspectos relativos a própria natureza laboral da equipe de $\mathrm{TI}$, que demanda que seu trabalho ocorra com a mesma dinâmica frenética que ocorre com a área, ou ainda, com a questão do individualismo de realização isolada da tarefa.

Assim pode-se perceber que a visão de conflitos dos indivíduos além de corroborar com os pressupostos conceituais sobre o tema, traduz ainda um aspecto intrínseco a sua aplicação na realidade dos componentes da equipe. Dito de outro modo, mesmo a equipe não considerando que ocorra conflito entre eles, o aspecto de dependência de outras áreas gera insatisfação uma vez que eles não podem desenvolver suas atividades no ritmo que gostaria. Essa insatisfação pode ser um potencial gerador de conflitos.

\subsection{POTENCIAIS GERADORES DE CONFLITO}

Foram respondidas questões relativas a percepção dos entrevistados em relação a potenciais geradores de conflitos. Um dos primeiros geradores observados foi a faixa etária que segundo eles, embora não ocorra internamente reconhecem que pode gerar conflitos por entender que diferenças de experiências de vida, geram possibilidades de discordâncias e consequentes conflitos. Porém a diferença etária para realidade da equipe, foi considerado como algo positivo que provoca a reciclagem do conhecimento.

Ao se discutir a possibilidade de gerência equivocada originar conflitos, eles responderam que entendem que isso pode ocorrer, mas que no caso da equipe de TI tanto nível operacional como no nível estratégico eles entendem que tem dois bons líderes que são conciliadores e que se estabelecem sua autoridade através do alto nível de conhecimento técnico.

O que se percebe pela análise do discurso é que o poder para a área de TI é consolidado através da demonstração de conhecimento. Além disso, aspectos de relacionamento e de conciliação de demandas são essenciais para o bom desempenho da liderança.

No que diz respeito busca pelo poder como gerador de conflitos, revelaram que por terem um setor tão enxuto não havia questões dessa natureza e que os papeis eram bem estabelecidos, mas que a nível institucional ocorre bastante disputa de poder e consequentes conflitos.

Quanto à busca de objetivos distintos da instituição e conhecimento específico não consideraram aspectos geradores de conflitos, embora a literatura observe que a falta de alinhamento dos objetivos organizacionais com os pessoais levam a insatisfação dos sujeitos que acabam partindo para outras empresas até mesmo para outras carreiras. Em relação ao aspecto de conhecimento específico os respondentes pensam que não geram conflitos mas sim aprendizados como explicado na próxima categoria de análise.

\subsection{DEMOCRATIZAÇÃO DAS INFORMAÇÕES}

As discussões acerca das ferramentas mais atualizadas algumas vezes é ponto de discussão de opiniões divergentes que ao invés de gerarem conflitos e competição geram a difusão das 
informações e de perpetuação do conhecimento válido e da eliminação de alternativas já utilizadas que foram pouco eficientes. Nesse sentido, os respondentes entre que essa discussão na equipe de Tl é salutar e traz novos conhecimentos em um processo de democratização do conhecimento. Além disso, a equipe trabalha com equipamentos de alta qualidade que é considerada por eles uma das vantagens em trabalhar na instituição.

\subsection{CONFLITOS INTERNOS}

Uns dos aspectos unânimes de conflitos na instituição são entre gerações de outras áreas da empresa. Como a equipe de TI são os responsáveis por criar ferramentas, treinar e implementar no dia-a-dia dos indivíduos eles percebem uma série de reclamações e discordância por indivíduos que segundo a equipe são resistente a mudanças de uma forma geral.

As mudanças tecnológicas, principalmente, uma vez que esses clientes internos sentem-se alheios ao seu próprio trabalho, já que quando se deparam com a nova ferramenta não sabem desenvolver o trabalho que há anos já desenvolvia. Esses indivíduos não conseguem perceber a agilidade, segurança e eficiência trazida pelas novas ferramentas e ficam presos a métodos obsoletos e a sistemas legados.

O que se pode observar ainda é que por se tratar de uma equipe que apresenta uma dinâmica diferenciada dos demais setores por questões intrínsecas a própria atividade, é que a instituição de características mecanísticas, não acompanha o mesmo ritmo de geração e modificação de processos provocados e/ou aperfeiçoados pela equipe de TI. Por outro lado, a equipe evidenciam como uma vantagem laboral a flexibilidade e um ritmo de cobrança menos intenso por se tratar de uma instituição pública, na qual eles julgam ter mais liberdade para criar sem a pressão psicológica em cumprir metas agressivas

Dessa forma, foram apresentadas as categorias de análise em relação à compreensão do padrão de comportamento interpessoal entre indivíduos que trabalham com inovações e como interagem com o ambiente organizacional e com sua equipe nos níveis estratégicos e operacional.

\section{CONSIDERAÇÕES FINAIS}

A análise acerca dos conflitos organizacionais e seus potenciais geradores observando as diferentes gerações (coortes), trouxe contribuições do ponto de vista do conhecimento sobre as "verdades" teóricas do tema e que aplicações empírica são observadas.

A equipe de $\mathrm{Tl}$ em uma instituição pública apesar de não apresentar o mesmo ritmo de metas que no setor privado (segundo os entrevistados) apresentam uma forma mais dinâmica de desenvolver os processos que modifica a rotina da organização.

Em linhas gerais pode-se observar que segundo o critério de percepção dos entrevistados, a diferença entre gerações e os respectivos padrões de modelos mentais são potenciais geradores de conflitos organizacionais. Porém, sob o ponto de vista da eficiência operacional e estratégica da equipe de $\mathrm{Tl}$ em estudo percebe-se que essa diferença de idade é pequena e tem pouca relação com as motivações de conflitos organizacionais. 
Também ficou sugerido que o comportamento da equipe é homogêneo e tem concentração dos indivíduos na geração $X$, o que corrobora para os preceitos teóricos observados que caracterizam esses indivíduos como avessos a ordens e que gostam de trabalhos independentes.

Isso indica que a partir da categoria da análise das relações interpessoais e trabalho em equipe, realizam projetos na equipe mas não desenvolvem trabalho em equipe. $O$ que ocorre é a somatória de trabalhos isolados que totalizam em resultados para um projeto determinado. Porém esses aspectos pode oportunizar perda de sinergia e de otimização dos processos.

Esse aspecto, no entanto é minimizado em virtude da democratização da informação, categoria de análise observada no campo empírico através do discurso dos respondentes que demonstram como aspecto positivos sobre algumas discussões do ponto de vista técnico (que não consideram como conflitos) eles tem a oportunidade de aprimorar seus conhecimentos pela difusão das ferramentas utilizadas. Essa prática (mesmo que pouco frequente) pode anular ou minimizar os efeitos da perda de sinergia observada pela não execução de trabalho em equipe.

Em se tratando da dimensão potencias geradores de conflitos, pode-se observar que apesar de não existiram conflitos na equipe em função da diferença etária, na percepção dos respondentes isso pode ser um gerador de conflito. Também foi observado que mesmo a equipe não considerando que ocorra conflito entre eles, o aspecto de dependência de outras áreas gera insatisfação uma vez que eles não podem desenvolver suas atividades no ritmo que gostaria. Essa insatisfação pode ser um potencial gerador de conflitos.

Os conflitos com clientes externos foi uma categoria de análise elencada que foi amplamente discutida no discurso e que merece atenção, uma vez que esses conflitos podem está sendo gerado pelas diferenças de gerações ou mais por uma questão relativa ao conhecimento específico.

Em relação ao conhecimento específico, no entanto, os entrevistados responderam que isso não deve configurar um potencial gerador de conflito, assim como busca por interesses pessoais diferentes da instituição. Essa percepção pode também está embebida pelo perfil mais independente dos respondentes.

Quanto à busca pelo poder como gerador de conflito, o grupo foi unânime que tanto do ponto de vista da percepção, como na realidade vivenciado no nível institucional, essa variável tem relação direta com conflitos organizacional.

Diante dessas questões é possível perceber que equipes que trabalham com uma modalidade de gestão matricial pautadas em projetos e que desenvolve suas tarefas com alta dependências de ferramentas tecnológicas priorizam o trabalho individualizado. Isso por um lado pode ser um neutralizador de atritos que por ventura poderiam ocorrer ou ainda poderá atritos velados que acabam sendo expostos em questões mais estratégicas. De uma forma geral as diferenças de gerações têm pouca relação com os conflitos organizacionais nesse tipo de equipe já que independentemente da idade busca-se manter o nivelamento do conhecimento.

\section{REFERÊNCIAS BIBLIOGRÁFICAS}

1. BARBOSA, Christian; CERBASI, Gustavo (2009). Mais tempo, mais dinheiro: estratégias para uma vida mais equilibrada. Rio de Janeiro: Thomas Nelson Brasil. 264p. 
2. BERGAMINI, Cecília Whitaker. 2005. Psicologia Aplicada à Administração de Empresas: Psicologia do comportamento organizacional. São Paulo: Atlas.

3. CALDAS, M. P. 2000. Demissão: causas, efeitos e alternativas para empresas e indivíduo. São Paulo. ATLAS.

4. CAVAZOTTE, F; LEMOS, A.H.C.; VIANNA, M. D.2010. Relações de Trabalho Contemporâneas e as Novas Gerações Produtivas: Expectativas Renovadas ou Antigos Ideais? XXXIV EnANPAD.

5. COHEN, Allan R.; FINK, Stephen. 2003. Comportamento Organizacional: Conceitos e estudos de caso. Rio de Janeiro: Editora Campus.

6. COIMBRA, R.G.C.; SCHIKMANN, R. A Geração Net; XXV .1998. In: ENCONTRO DA CONGER, Jay. Quem é a geração X? HSM Management, n.11, p.128-138, nov./dez.

7. FERREIRA, Humberto Medrado Gomes. 2007. Conflito Interpessoal em equipes de trabalho: O papel do líder como gerente das emoções do grupo. Disponível em: <http://www.aedb.br/seget/artigo07/1271_SEGET_2_2007_2.pdf>. Acessado em: 20 ago 2011.

8. GIACCHETTO, Cybele Padoan.2008. Grupo $\mathbf{x}$ Equipe. Disponível em: <http://www.administradores.com.br/informe-se/artigos/grupo-x-equipe/25857/>.

Acessado em: 25 julho 2011.

9. GIL, Rosalina. Análise de discurso. 2002. In: BAUER, Martin W.; GASKEL, George. Pesquisa qualitative com texto, imagem e som: um manual prático. 4 ed. Tradução Pedrinho Guaresh. Petrópolis, RJ: Vozes.

10. HITT, Michael A.; MILLER, C. Chet; COLELLA, Adrienne.2006. Comportamento Organizacional: Uma Abordagem Estratégica. Rio de Janeiro: LTC.

11. LOMBARDIA, P.G.; STEIN, G.; PIN, J.R.2008. Politicas para dirigir a los nuevos profesionales motivaciones y valores de la generacion Y. Documento de investigación. DI-753, 2008. Disponível em: http://www.iesep.com/Descargas/spdf/Gratuitos/R130.pdf. Acessado em 30 Jul 2011.

12. MAXIMIANO, Antonio Cesar Amaru.2004. Fundamentos de administração: Manual compacto para as disciplinas de TGA e Introdução à administração. São Paulo: Atlas.

13. PORTES, G. E. P. 2009 . Geração Y - características e liderança: uma discussão sobre a importância do autoconhecimento no desenvolvimento da confiança e de uma cultura da transparência para estes líderes. In: VI EPEGE Encontro Paranaense de Empreendedorismo e Gestão Empresarial, 2009, Ponta Grossa, PR. Anais do Evento VI EPEGE Encontro Paranaense de Empreendedorismo e Gestão Empresarial.

14. ROBBINS, Stephen P.2005. Comportamento organizacional. São Paulo: Peason Prentice Hall.

15. RUBIN, J. K.; PRUITT, D. G.; KIM, S. H.. 1994. Social Conflict: Escalation, stalemate and settlement. Second Edition. New York: McGraw-Hill, Inc.

16. SOUZA, Sérgio Luiz Baena de. 2011. Fatores que influenciam os consumidores da Geração "Z" na compra de produtos eletrônicos. Dissertação (Mestrado em Administração). Universidade Potiguar, Natal.

17. TAPSCOTT, D. 2008. Geração $Y$ vai dominar força de trabalho. ITWEB. Disponível em < http://informationweek.itweb.com.br/296/geracao-y-vai-dominar-forca-de-trabalho/> 
Acessado em 30 Jun 2011.

18. TAPSCOTT, Don. 2010. A hora da geração digital: como os jovens que cresceram usando a internet estão mudando tudo... Tradução de: Marcello Lino. Rio de Janeiro: Agir. Tradução de Grown up digital: how the net generation is changing your world. 448p.

19. TOFFLER, Alvin. 2001. A terceira onda. São Paulo: Record. 26a ed., 492p.

20. VASCONCELOS, K. C. A. ; MERHI, D. Q ; LOPES, V. M. G ; LEITE-DA-SILVA, A. R .2009. A Geração Y e Suas Âncoras de Carreira. In: EnGPR - Encontro de Gestão de pessoas e relações do trabalho, 2009, Curitiba. II EnGPR - Encontro de Gestão de pessoas e relações do trabalho.

21. VELOSO, Elza Fátima Rosa; Dutra, J.S.; Nakata, L. E. 2008. Percepção sobre carreiras inteligentes: diferenças entre as gerações $Y, X$ e baby boomers. In: ENCONTRO DA ASSOCIAÇÃO NACIONAL DE PÓS-GRADUAÇÃO EM ADMINISTRAÇÃO, 32., 2008, Rio de Janeiro. Anais... Rio de Janeiro: ANPAD.

22. VergarA, Sylvia Constant. 2009. Gestão de Pessoas. São Paulo: Atlas.

23. VERIGUINE, Nádia Rocha; BASSO, Claudia ; SOARES, D. H. P..2010 . A PERCEPÇÃO DOS JOVENS DA GERAÇÃO Y SOBRE O CONCEITO TRABALHO. In: I Jornada Internacional de práticas clínicas no campo social, 2010, Maringa. ANAIS I Jornada Internacional de práticas clínicas no campo social. Maringa : Editora da Universidade de maringa. v. 1.

24. ZEMKE, Ron; RAINES, Claire; FILIPCZAK, Bob.2000. Choque de Gerações. Disponível em: <http://www.centroatl.pt/edigest/edicoes2000/ed_mar/ed65cef-capa.html>. Acessado em: 30 jun. 2011. 